\title{
The Impact of DC-power Layout on Stray Inductance of Bridge Arm in Power Converters
}

\author{
Yi-feng Zhu ${ }^{1, *}$, Hai-jun Tao ${ }^{1}$ and Qiong-xuan $\mathrm{Ge}^{2}$ \\ ${ }^{I}$ School of Electrical Engineering and Automation, He'nan Polytechnic University, JiaoZuo City, Henan Provence, Chi- \\ na \\ ${ }^{2}$ Key Laboratory of Power Electronics and Electric Drive, Institute of Electrical Engineering, Chinese Academy of Sci- \\ ences, Beijing, China
}

\begin{abstract}
In high power converter design, low-inductance busbar connecting DC capacitors and power devices is the main concern to improve the quality of the whole power electronics system. There are several facts which affect the stray inductance of bridge arm. This paper mainly analyzes the influence of DC-power layout on the stray inductance taking a subway traction converter as example. The Psim9.0 software was used to calculate the stray inductance. The conclusion is that DC-power connection should be put different side from DC capacitance because lower stray inductance can be obtained than that of the same side. The simulation and experimental results are given to illustrate the effectiveness.
\end{abstract}

Keywords: DC-power connection, high-power converters, stray inductance,

\section{INTRODUCTION}

In high power converters, the stray inductance existing in the commutation loop should be as low as possible considering safe and high-efficiency operation of switch devices and converters. In fact, the stray inductance distributed in the DC bus usually accounts for the main part of the whole loop inductance [1]. The oversize stray inductance distributing on the busbar, which links DC capacitor bank to converter power devices, may bring excessive transient voltage overshoots, which can result in high voltage stress, increased heating/power losses and exceeding of the device safe operating area [2].

There are many literatures on the study of converters design to decrease the stray inductance in different aspects [17]. Skibinski [3] compared various busbar shapes in terms of internal and external impedance to show the superior performance of a parallel plate structure. Dimino [4] discusses the application of a laminar busbar structure. A laminatedstructure bus bar provides as low effective inductance as possible for a converter. This construction allows for the largest mutual inductance mitigation directly along the power distribution path [5]. The closer these plates are laminated together, the more the mutual cancellation that will be realized [6]. Reference [7] proposed to achieve the optimal busbar design by genetic algorithms.

In this paper, we will focus our study on the impact of DC-power connection on the stray inductance of bridge arm in high-power converters. Suitable DC-power connection

\footnotetext{
*Address correspondence to this author at the School of Electrical Engineering and Automation, Henan Polytechnic University, 2001 Century Avenue, Jiaozuo (454003), Henan, P.R. China; Tel/Fax: 086-13693916259;

E-mail:zyfny@hpu.edu.cn
}

should be put different side of DC capacitance because lower stray inductance can be obtained than that of the same side. A subway traction converter is taken as an example to analyze the impact, including two-layer busbar and three-layer busbar. Firstly, the analytical model of multi-layer busbar is set up to obtain the stray inductance. Then, some simulation and experimental results are given to validate the conclusion further.

\section{THE IPSILATERAL LAYOUT OF DC POWER AND DC CAPACITANCE}

To high-power converters the DC power can be put the same side with DC capacitance and the different side from DC capacitance as well. Because the connection of DCpower to power switches has stray inductance which affects the bridge-arm stray inductance, it is valuable to study the suitable layout between ipsilateral layout and both-sides layout.

Fig. (1) shows the ipsilateral-layout circuit of DC power and DC capacitance. Assume that the circuit parameters are shown as Fig. (1). The suppose matches well with actual application and is reliable. The stray inductance of DC capacitance and DC busbar is about $20 \mathrm{nH}$ and $26 \mathrm{nH}$, respectively. The parasitic inductance of each power semiconductor is approximately $12 \mathrm{nH}$. To the DC power connection its stray inductance depends on the connection length. Now some study will be done under the two connection induction of $50 \mathrm{nH}$ and $500 \mathrm{nH}$.

Some simulation has been finished on the circuit mentioned above and the waveforms of the current flowing through DC power $I_{\mathrm{s}}$ and the current flowing DC capacitance $I_{\text {cap }}$ is given as Fig. (2). In the figure $i_{\text {cir }}$ and $i_{\text {cir } 2}$ indicate the circle current flowing through DC capacitance and DC pow- 


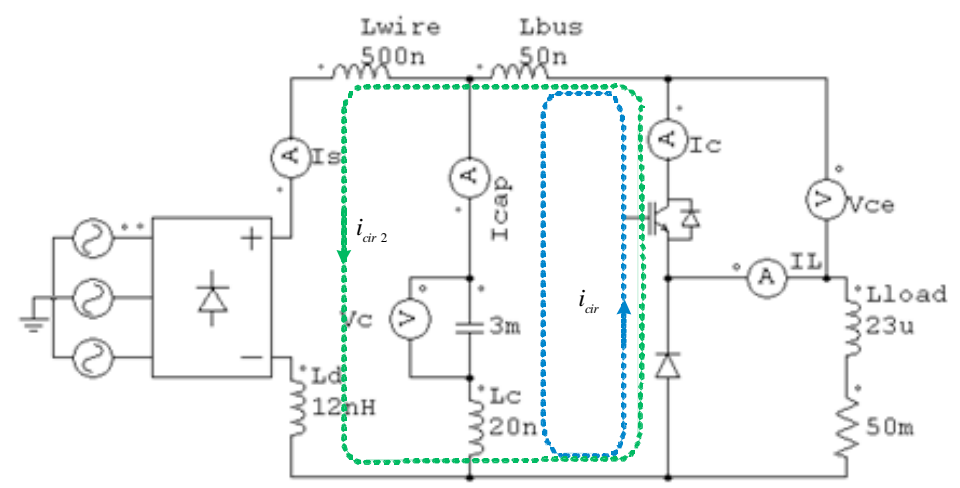

Fig. (1). The ipsilateral layout of DC power and DC capacitance.

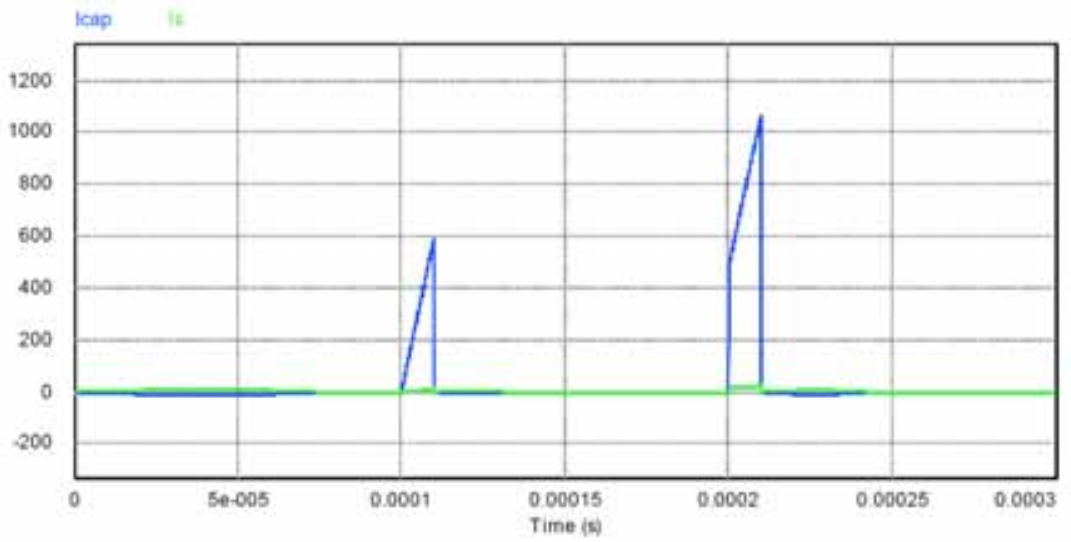

(a) $L_{\text {wire }}=500 \mathrm{nH}$

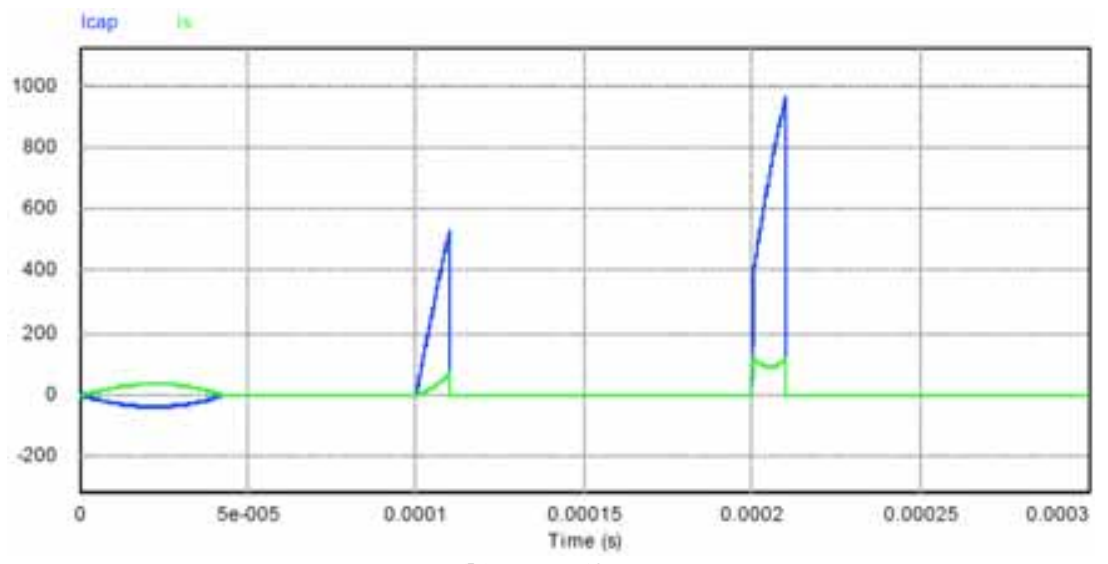

(b) $L_{\text {wire }}=50 \mathrm{nH}$

Fig. (2). The power current $I_{\mathrm{s}}$ and the DC-capacitance current $I_{\text {cap }}$ while the ipsilateral layout.

er, respectively. In fact, it is the inductance of the circle circuit which the circle current flows that affects the overshoot voltage of the IGBT which turns off. From Fig. (2) one can see that the current distributed in DC power and capacitance is not equal under different connection inductance of DC power. When the stray inductance of DC connection from DC power to capacitance is large $(500 \mathrm{nH})$, the circle current flowing DC power is very small and the load-current is almost made up of the capacitance current. So it can be considered that the circlecurrent circuit is composed by only the circle circuit including DC capacitance when IGBT turns off as shown in Fig.1. Based on the above analysis the total stray inductance $L_{\mathrm{za}}$ of the bridge arm can be obtained as formula (1).

$$
L_{z a}=2 L_{I G B T}+L_{b u s}+L_{C}
$$

Where $L_{\mathrm{IGBT}}, L_{\text {bus }}, L_{\mathrm{C}}$ is the stray inductance of IGBT, DC busbar and DC capacitance, respectively. It should be noted that each circle-current circuit includes two power switches.

When the stray inductance of DC connection from DC power to capacitance is smaller $(50 \mathrm{nH})$, the circle current flowing DC power increases and cannot be neglected. So the circle-current circuit is composed by two circuits. One is the circle circuit through DC power and the other is the circle circuit including DC capacitance when IGBT turns off as shown in Fig. (1). Based on the above analysis the total stray 


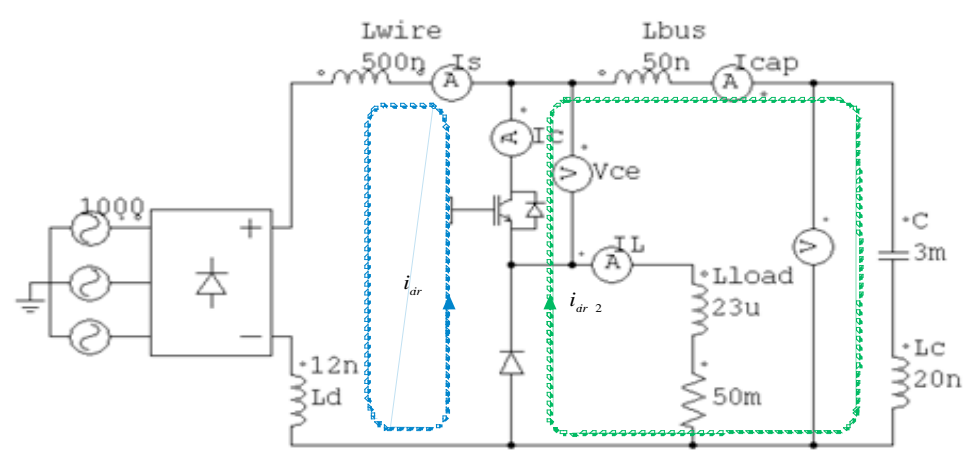

Fig. (3). The both-sides layout of DC-power and DC capacitance.

inductance $L_{\mathrm{za}}$ of the bridge arm can be obtained as formula (2).

$$
L_{z a 1}=2 L_{I G B T}+L_{b u s}+L_{C} / /\left(L_{\text {wire }}+L_{d}\right)
$$

Where Lwire, Ld indicate the inner stray inductance of connection wire from DC power to capacitance and the power switch in the rectifier power. From formula (2) it can be seen that the stray inductance of the non- overlapping part of the two circle-current circuit as shown in Fig. (1) is in parallel-connection. So the total parasitic inductance is smaller than the value calculated by formula (1). This result indicates that the stray inductance of connection from DC power to capacitance tank affects the parasitic inductance of the bridge arm. And the connection inductance is smaller, the smaller the stray inductance of the bridge arm. So in order to minimize the bridge-arm stray inductance the connection stray inductance from DC power to capacitance tank should also be designed to low inductance as well as the DC busbar. If the power supply is battery, the laminated busbar connection power to capacitance can be adopted. But to the remote $\mathrm{DC}$ rectifier power it is difficult to design low inductance unless reducing the length of connection wire.

\section{THE BOTH-SIDES LAYOUT OF DC POWER AND DC CAPACITANCE}

DC power is usually put the same side with the DC capacitance as analyzed in the $2^{\text {nd }}$ section. In fact, DC power can be set the different side from capacitance tank, which is named as both-sides layout. The stray inductance of the both-sides layout is possible to be smaller than the ipsilateral layout.

Fig. (3) gives the circuit of the both-sides layout of DCpower and DC capacitance tank. The device parameters are the same with the parameters shown in Fig. (1). From Fig. (3) one can see that there exist two circle-current circuits noted as $i_{\text {cir }}$ and $i_{\text {cir2 }}$ at the same time when IGBT turns off under the both-sides layout.

Fig. (4) gives the waveforms of the circle-current $i_{\text {cir }}$ and $i_{\text {cir2 }}$ simulated by Psim9.0 with different power-connection stray inductance of $50 \mathrm{nH}$ and $500 \mathrm{nH}$. One can see that the power wire inductance smaller the larger the circle-current flowing DC power. Furthermore, the circle-current through DC power is much larger under both-sides layout than under ipsilateral layout with the same power-connection inductance. This means that the power-connection inductance under both-sides layout has heavier impact on the bridge-arm stray inductance compared with the same-sides layout. Even if the power-connection stray inductance is very large such as $500 \mathrm{nH}$ it can reduce the bridge-arm parasitic inductance. Therefore, in order to reduce the bridge-arm inductance to maximum extent the both-sides layout of DC power and DC capacitance tank prefers to the ipsilateral layout.

If one analyzes the circuit structure, the total stray inductance $L_{\mathrm{za}}$ of the bridge arm, which affects significantly the turn-off overshoot voltage, can be obtained as formula (3).

$$
L_{z a 2}=2 L_{I G B T}+\left(L_{b u s}+L_{C} / /\left(L_{\text {wire }}+L_{d}\right)\right.
$$

From formula (3) it can be seen that the stray inductance of non-overlapping part of the two circle-current circuits is equivalent parallel-connection. So the total calculated stray inductance will be smaller than the value calculated by formula (2).

Table 1. The comparison of stray inductance under two different layout of DC power.

\begin{tabular}{|c|c|c|}
\hline Stray Inductance & Ipsilateral Layout & Both-sides Layout \\
\hline \hline $\mathrm{L}_{\mathrm{wire}}=500 \mathrm{nH}$ & 81 & 74 \\
\hline $\mathrm{L}_{\mathrm{wire}}=50 \mathrm{nH}$ & 77 & 45 \\
\hline
\end{tabular}

\section{SIMULATION AND COMPARISON}

Supposing that the power-connection stray inductance is equal to $50 \mathrm{nH}$ and $500 \mathrm{nH}$, respectively, the bridge-arm parasitic inductance under ipsilateral layout and both-sides layout of DC power and capacitance tank is simulated by Psim 9.0 and compared as shown in Table 1. A more detailed comparison is given in Fig. (5). It can be seen from the figure that the bridge-arm stray inductance under both-sides layout of DC power and capacitance tank is always smaller than the same-sides layout, especially when the power-connection inner inductance is smaller than $300 \mathrm{nH}$. When the powerconnection parasitic inductance is larger than $300 \mathrm{nH}$, the bridge-arm stray inductance obtained under the two different layout of DC power is very close to each other. 


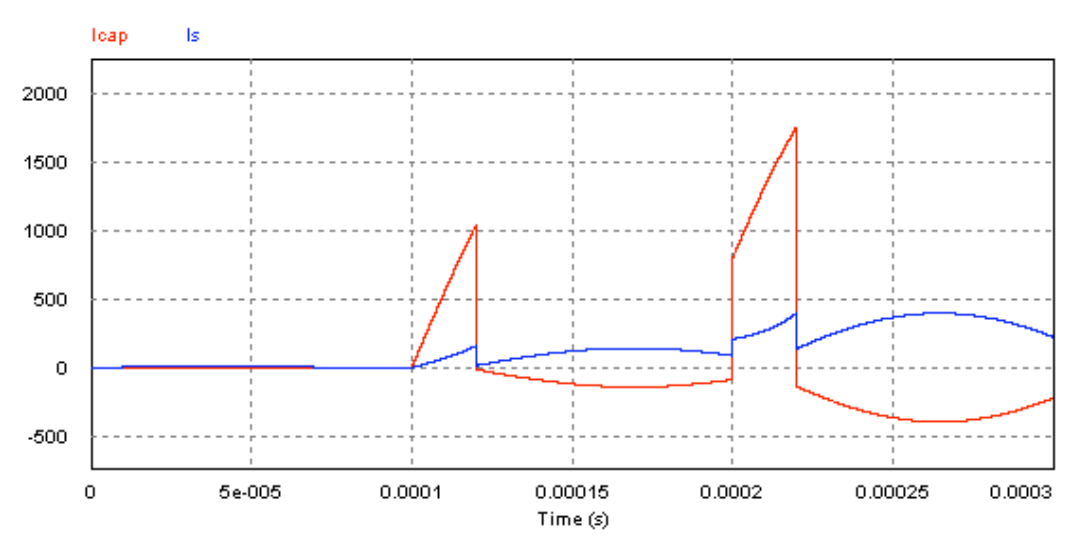

(a) $L_{\text {wire }}=500 \mathrm{nH}$

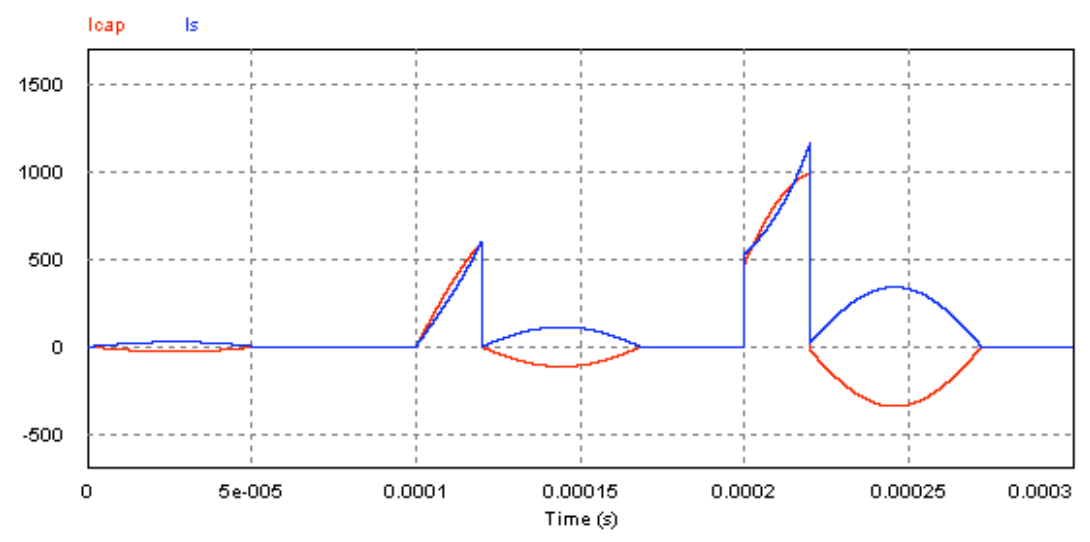

(b) $L_{\text {wire }}=50 \mathrm{nH}$

Fig. (4). The power current $I_{\mathrm{s}}$ and the DC-capacitance current $I_{\text {cap }}$ while the both-sides layout.

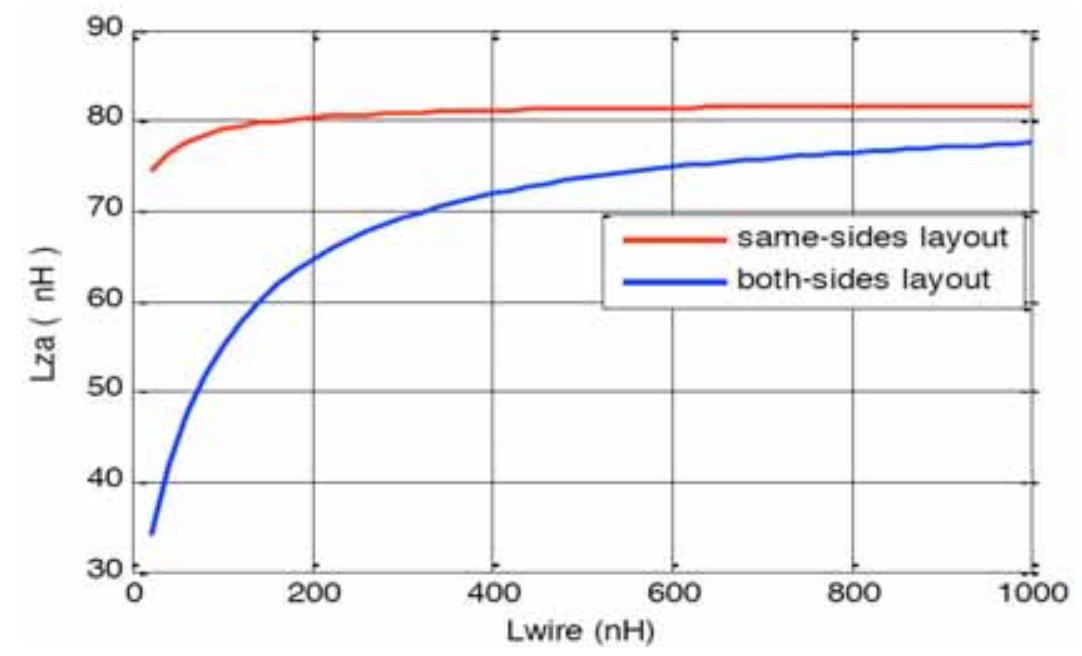

Fig. (5). The impact of the power-connection inductance on the bridge-arm inductance under different layout of DC power.

\section{EXPERIMENTAL RESULTS}

To validate the conclusion drawn in the up section some experiments are given on a three-layer busbar used in subway traction converter with the power of $3 \mathrm{WM}$.

Fig. (6) shows the experimental circuit to test the stray inductance, where $\mathrm{A}$ and $\mathrm{B}$ are high-voltage probe and Rogowski coil, respectively. And Fig. (7) gives the experimental waveform of the up power device in arm1 under three-layer busbar. One can see that the overshoot voltage is about $400 \mathrm{~V}$, and the work current is equal to $1200 \mathrm{~A}$. And the computed stray-inductance of the busbar $\left(L_{\mathrm{za}}\right)$ is approximately $134 \mathrm{nH}$ by the mathematical formula as (4). The simulation and experimental results match well.

$$
L_{z a}=\frac{U_{o v}}{I_{n}} t_{f}
$$




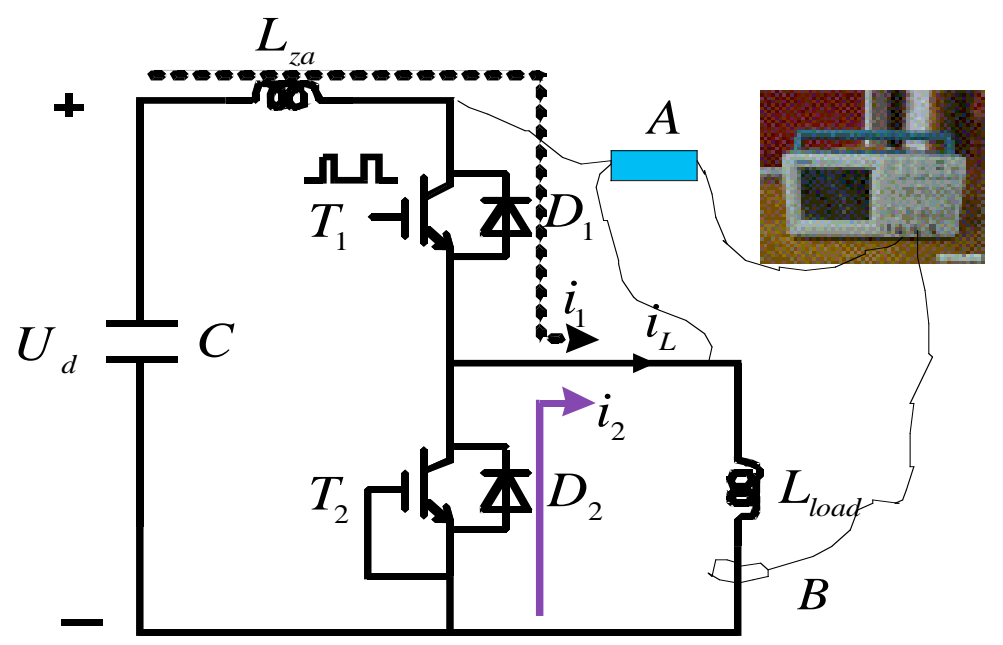

Fig. (6). The test circuit of the stray inductance.

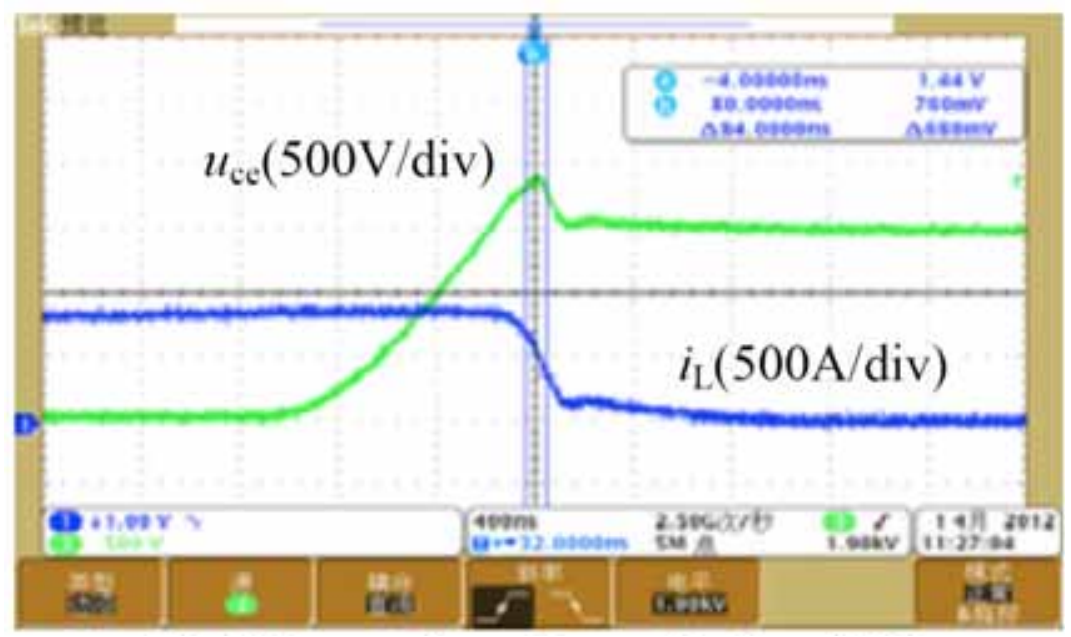

Fig. (7). The waveform of $u_{\mathrm{ce}}$ and $i_{\mathrm{c}}, \Delta u_{\mathrm{ce}}=400 \mathrm{~V}$.

Where, $U_{\mathrm{ov}}$ is the overshoot voltage born by the switch device which changed from turn-on to turn-off, $I_{\mathrm{n}}$ is the electrical current flowing in the $\mathrm{H}$-bridge circuit when the $\mathrm{H}$ bridge works normally, and $t_{\mathrm{f}}$ is the time during for the current from $I_{\mathrm{n}}$ to zero.

\section{CONCLUSION}

Stray inductance is an important concern in high power converter design. Low inductance and oscillation planar busbar have played a significant role in reducing EMC problems caused by stray inductance.

The paper analyzes detailed the impact of the powerconnection stray inductance on the bridge-arm parasitic inductance under different layout of DC power and capacitance tank. The results show that the stray inductance of power-connection affects the parasitic inductance of the bridge arm. And the connection inductance is smaller, the smaller the stray inductance of the bridge arm. Furthermore, the bridge-arm stray inductance under both-sides layout of DC power and capacitance tank is always smaller than the same-sides layout.

\section{CONFLICT OF INTEREST}

The authors confirm that this article content has no conflict of interest.

\section{ACKNOWLEDGEMENTS}

This work was supported by scientific and technology research fund of Henan provincial education department (Project No. 14A470005) and Key Laboratory of control engineering of Henan Province, Henan Polytechnic University (Project No. KG2014-15).

\section{REFERENCES}

[1] Z. Yi-feng, G. Qiong-xuan, "Study on busbar-structure for prototype of the high-speed railway traction converter", Proceedings of 2011 International Conference on Electrical and Control Engineering, 2011, pp. 3177-3180.

[2] C. Caponet, F. Profumo, R. W. De Doncker, A. Tenconi. "Low stray inductance bus bar design and construction for good EMC performance in power electronic circuit", IEEE Trans Power Electron, vol. 17, no. 2, pp. 225-231, 2002.

[3] Z. Wang; G. Chen, "Study on planar busbar regarding stray inductance minimization and oscillation suppression for high power con- 
verter", Sustainable Power Generation and Supply, International Conference, pp. 1-7, 2009.

[4] H. Wen, X. Wen, J. Liu, X. Guo, F. Zhao, A low-inductance highfrequency film capacitor for electric vehicles, International Conference on Electrical Machines and Systems, ICEMS. pp. 2046-2050, 2007.

[5] R.J. Pasterczyk, C. Martin, J.-M. Guichon, J.-L. Schanen, Planar busbar optimization regarding current sharing and stray induct- ance minimization, European Conference on Power Electronics and Applications, pp. 90- 95, 2005.

[6] F. Zare, G.F. Ledwich, "Reduced layer planar busbar for voltage source inverters", Power Electronics, IEEE Transactions vol. 17 no. 4, pp. 508-51, 62002.

[7] L. F. Zheng; S. Xudong; H. Lipei, J. Jianguo, Parasitic parameters of capacitor tank in converter and the effect on switching transient process, Vehicle Power and Propulsion Conference, VPPC '09, IEEE, pp. 736-739, 2009.

Received: June 09, 2014

Revised: June 22, 2014

Accepted: July 24, 2014

(c) Zhu et al.; Licensee Bentham Open.

This is an open access article licensed under the terms of the Creative Commons Attribution Non-Commercial License (http://creativecommons.org/licenses/by-nc/3.0/) which permits unrestricted, non-commercial use, distribution and reproduction in any medium, provided the work is properly cited. 